Original Research Paper

\title{
End Discharge Relationship for Free Overfall Affected by Upstream Bed Roughness and Slope
}

\author{
Jaafar S. Maatooq \\ Hydraulic Structures, Building and Construction Engineering, University of Technology-Baghdad, Iraq
}

Article history

Received: 01-04-2017

Revised: 04-04-2017

Accepted: 05-06-2017

Email: jaafarmaatooq@gmail.com 40071@uotechnology.edu.iq

\begin{abstract}
The experimental program of this paper was restricted to free vertical drop structure at the end of the rectangular channel. The roughness and slope of the bed of approach channel are the aim of this study to show their effects on End Depth Ratio (EDR). Three different roughness from smooth $(n=0.009)$ to rough $(n=0.019)$ with four-bed slopes from horizontal $\left(S_{o}=0\right)$ to $S_{o}=0.01$ were adopted with total 72 runs. The analysis of experimental data was focused on the variation of EDR as a roughness and/or bed slope changed. Also, the design formulas have been derived statistically for numerous practical situations and recommended to be used as predictive equations for both EDR and discharge.
\end{abstract}

Keywords: Free Overfall, Vertical Drop, End Depth Ratio, Bed Roughness, Horizontal Slope

\section{Introduction}

The overfall (drop) structures are hydraulic structures frequently uses in irrigation canals especially when the canal lied within a steep topography. The drop is also considered as the unit building feature of stepped spillway and cascades. The overfall then refers to the downstream portion of a horizontal or sloping channel, if it does not submerge by the tail water it is called to as a "free overfall". The brink section divides the flow into the upstream zone bounded by channel boundary and into the unbounded downstream jet zone. The jet due to a free falling flowed as a nappeat the end of the drop. Thus the assumption of hydrostatic pressure distribution that exists further upstream (i.e., at a location still not influenced by the drawdown of flow) does not still exist at the brink. At this state the curvilinear of streamlines at the brink of the drop make the pressure distribution to become under the influence of gravitational acceleration. In discharge relationships for any flow measuring structures, the head that governed the calculation should be measure at a section of parallel streamlines that insure the pressure distribution is hydrostatic. Numerous experimental research focused on measuring the brink depth, $y_{b}$ and relate it to a critical depth, $y_{c}$. This relation called End Depth Ratio (EDR). It could become easy to use a drop as a measuring flow structure by using this ratio. The $y_{b}$ located at a discharge measuring structure has attracted considerable interest for a wide number of theoretical and experimental studies such as; Rouse
(1936; Fathy and Shaarawi, 1954; Delleur et al., 1956; Diskin 1961; Smith, 1962). More recently studies restricted on EDR has been done by Davis et al. (1998; Ferro, 1999; Hong et al., 2010; Liu et al., 2014). In most of these studies, the upstream bed slope of free overfall was considered horizontal. On the other hand, the effect of roughness does not take considerably into a proposed predictive relationship. The present study work was conducted in the laboratory to investigate the effect of bed slope and roughness of upstream reach of drop structure on EDR. The state of flow was subcritical for all experimental runs. The results have been analyzed to propose a discharge prediction formula depends on the measurements of brink and normal depths.

\section{Experimental Work}

The experiments conducted in a glass side adjustable bed slope flume $5 \mathrm{~m}$ long, $8.6 \mathrm{~cm}$ width and $30 \mathrm{~cm}$ in depth located at Hydraulic Laboratory of the UOTBaghdad. The water enters the working section after passing through a rotameter type flow meter with $\pm 1 \%$ accuracy. The depths were measured using digital point gauge. The discharge was range between $1.5-10 \mathrm{~m}^{3} / \mathrm{hr}$. The plastic glass sheets $122 \mathrm{~cm}$ length, $8.6 \mathrm{~cm}$ width and $0.8 \mathrm{~cm}$ in thickness used as a bed surface of the drop. These sheets fixed at $12 \mathrm{~cm}$ above the bed of flume, this difference in elevation considered a simulation of vertical drop between a rectangular section channels portions upstream and downstream, Fig. 1. Two 
uniforms graded cohesion less type material grouped within sand and gravel ranges has $d_{50}=0.45 \mathrm{~mm}$ and $d_{50}=$ $4 \mathrm{~mm}$ were used for a roughening bed. The granular material was spread onto the surface of the plastic sheet and glued by an adhesive material, Fig. 2. Accordingly, three types of roughness were created to simulate a bed of channel before the drop; these are; smooth type, where the skin of plastic sheet was use without adding roughened elements, the second and third types has been with glued sand and gravel. The experiments were conducted at four different bed slopes with each roughness by adjusting the bed of flume. These slopes are a horizontal $\left(S_{o}=0\right)$ and three inclinations; $S_{o}=0.0025,0.005$ and 0.01 . Accordingly, three groups of experiments included 72 runs 6-runs at different discharges for each slope were adopted. In each run, after the desired slope fixed, the valve was adjusted to achieve desired discharge, a depths measured via point gauge and recorded in data sheet after the steady flow exists in the flume.

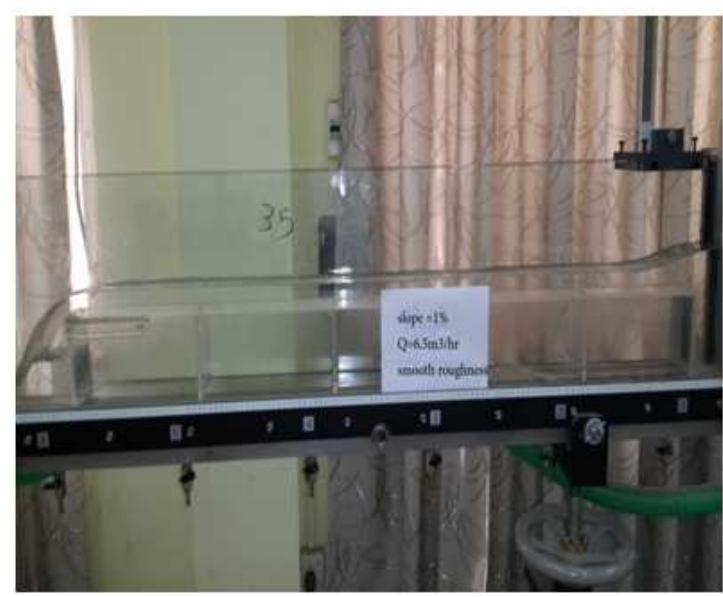

Fig. 1. Overfall under operation

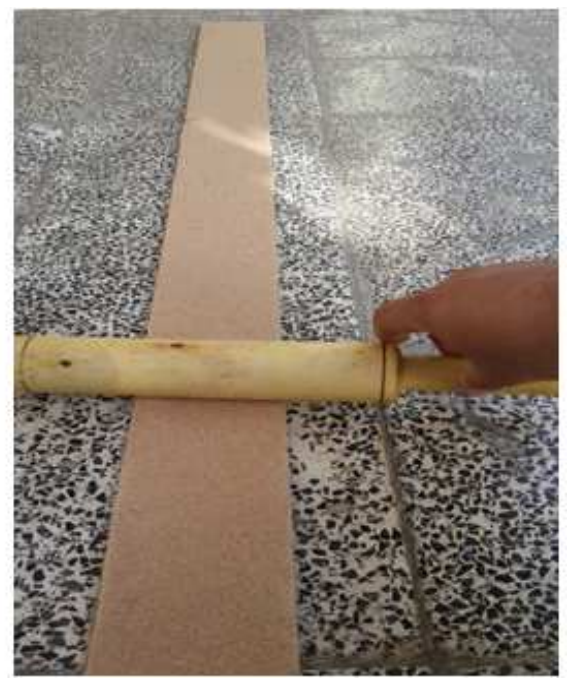

Fig. 2. Roughening bed

\section{Analysis of Experimental Results}

First of all, the roughness values of bed, $n$, those adopted in analysis calculated by using Strickler formula:

$n=\frac{d_{50}{ }^{1 / 6}}{21.1}$

where, $d_{50}$ is median particle size in $(\mathrm{m})$ and $\mathrm{n}$ is a roughness coefficient. Thus, two roughness coefficients as the results of Equation 1, these are; $n=0.013$ and 0.019 for sand and gravel have been adopted in present study respectively. For smooth sheet $n=0.009$ was taken to represent the roughness coefficient, this value usually uses for glass and Lucite surfaces (Mays, 2010). For each run two flow depths were measured, the first one located upstream where the water surface completely parallel to the bed, this depth recorded as a normal depth, $y_{n}$. The second measurement was depth on the brink of drop denoted as $y_{b}$. It should be noted here; the Manning's equation used to check the measurement of $y_{n}$ for verification. The critical depth, $y_{c}$ calculated from classical formula related a critical depth of the unit discharge for rectangular channels:

$$
y_{c}=\sqrt[3]{\frac{q^{2}}{g}}
$$

As previously stated, the end depth ratio, EDR is a flow depth at the brink, $y_{b}$ to the critical flow, $y_{c}$. In the current study, this ratio was firstly examined for horizontal slope at different bed roughness as illustrated in Fig. 3. This figure shows a little variation of EDR with roughness, but the less $y_{b}$ recorded when $n=0.019$. Figure 4 to 6 shows the EDR for each slope of inclined bed with different roughness. It is evident also from these figures that the minimum values between $y_{b}$ and $y_{c}$ were with $n=0.019$ for all slopes and the leaser one was at $S_{o}=0.0025$. However, no regular trend of EDR can recognize with the variation of the slope. This conclusion depicted in Fig. 7, where observing a little effect of slope beside unfixed tendency with the increasing of bed slope. These results encourage the extracting a general relationship between brink depth and critical flow depth. The trend line in Fig. 8 refers to that $y_{b} / y_{c}=0.7152$ with $R^{2}=0.983$. The values of EDR for the cases depicted in Fig. 3 to 7 listed in Table 1. Referring to the relationship of Fig. 8, it is worth a good agreement with this recommended by Rouse (1936) for a smooth rectangular horizontal channel and nearly agreement with Kraijenhoff and Dommerholt (1977) whose found $y_{b} / y_{c}=0.714$ for inclined bed up to 0.0025 . That confirms the Rajaratnam and Muralidhar (1964a; 1964b) finding, where they proved experimentally that, for 
different shapes of the channel cross section and a subcritical flow, the EDR is quasi-constant. Almost previous experimental works at rectangular channel cross sections provide that $y_{b} / y_{c}$ vary from 0.705 to 0.781 (Ferro, 1992). In present work, with using three different roughness and four bed slopes, the value of EDR ranged between $0.676-0.749$. The lower limit of this range is well agreed with value 0.673 which previously presented by Ali and Sykes (1972) by using free vortex theory, while the upper value is in agreement with 0.745 which reported by Gupta et al. (1993). However, the study was done by Delleur et al. (1956) shows that independent of roughness on $y_{b} / y_{c}$, while present work showed that the roughness has some sensitivity to influence on the values of EDR. This sensitivity appreciably noticed when $n=$ 0.013 to 0.019 , thereby the roughness induced to greater effect as it increases, that well observed in Fig. 10. Previous studies do not correlate between the EDR and the bed slope. However, two investigations, at hand, were proposed specified relationships related $y_{b} / y_{c}$ as a function of So. Davis et al. (1998) obtained for the aggregated roughness data a best fit quadratic equation in the following form:

$$
\frac{y_{b}}{y_{c}}=134.84 S_{o}^{2}-12.66 S_{o}+0.778
$$

The other research conducted by Firat (2004) at which the authors recommended two formulas, the first for smooth bed $(n=0.0091)$ and the second for application with roughened bed $(n=0.0147)$. These formulas for smooth and rough bed respectively are:

$$
\begin{aligned}
& \frac{y_{b}}{y_{c}}=0.77-2.05 \sqrt{S_{o}} \\
& \frac{y_{b}}{y_{c}}=0.76-1.29 \sqrt{S_{o}}
\end{aligned}
$$

The correlation between $y_{b} / y_{c}$ and $S_{o}$ of the current study produced three of third-degree relationships each of which depends on a specified roughness. The formulas of these equations for $n=0.009$ to $n=0.019$ are respectively:

$$
\begin{aligned}
& \frac{y_{b}}{y_{c}}=-253333 S_{o}{ }^{3}+3420 S_{o}{ }^{2}-11.76 S_{o}+0.734 \\
& \frac{y_{b}}{y_{c}}=-328000 S_{o}{ }^{3}+4940 S_{o}{ }^{2}-17.1 S_{o}+0.749 \\
& \frac{y_{b}}{y_{c}}=-360000 S_{o}{ }^{3}+5740 S_{o}{ }^{2}-22.1 S_{o}+0.701
\end{aligned}
$$

Table 1. Values of EDR for tested cases

\begin{tabular}{llll}
\hline $\begin{array}{l}\text { Slope of } \\
\text { upstream } \\
\text { Bed }\left(S_{o}\right)\end{array}$ & $\begin{array}{l}\text { Roughness of } \\
\text { upstream } \\
\text { channel }(\mathrm{n})\end{array}$ & $\mathrm{EDR}\left(y_{b} / y_{c}\right)$ & $\mathrm{R}^{2}$ \\
\hline Horizontal & 0.009 & 0.7340 & 0.9980 \\
Horizontal & 0.013 & 0.7494 & 0.9980 \\
Horizontal & 0.019 & 0.7007 & 0.9950 \\
0.0025 & 0.009 & 0.7218 & 0.9920 \\
0.0025 & 0.013 & 0.7317 & 0.9950 \\
0.0025 & 0.019 & 0.6759 & 0.9760 \\
0.0050 & 0.009 & 0.7289 & 0.9950 \\
0.0050 & 0.013 & 0.7463 & 0.9920 \\
0.0050 & 0.019 & 0.6891 & 0.9950 \\
0.0100 & 0.009 & 0.7056 & 0.9930 \\
0.0100 & 0.013 & 0.7442 & 0.9950 \\
0.0100 & 0.019 & 0.6938 & 0.9975 \\
Horizontal & All roughness & 0.7280 & 0.9920 \\
0.0025 & All roughness & 0.7100 & 0.9780 \\
0.0050 & All roughness & 0.7210 & 0.9850 \\
0.0100 & All roughness & 0.7140 & 0.9880 \\
\hline
\end{tabular}

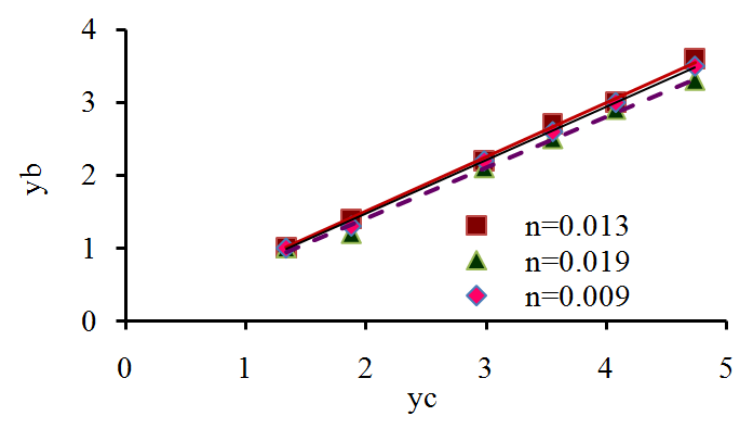

Fig. 3. EDR for $S_{o}=0$ and all roughness

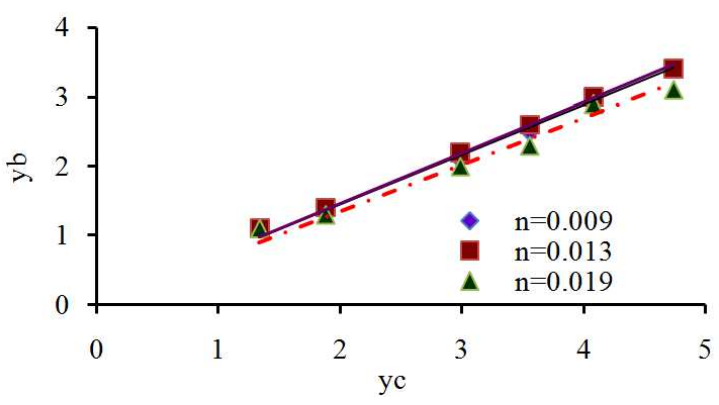

Fig. 4. EDR for $S_{o}=0.0025$ and all roughness

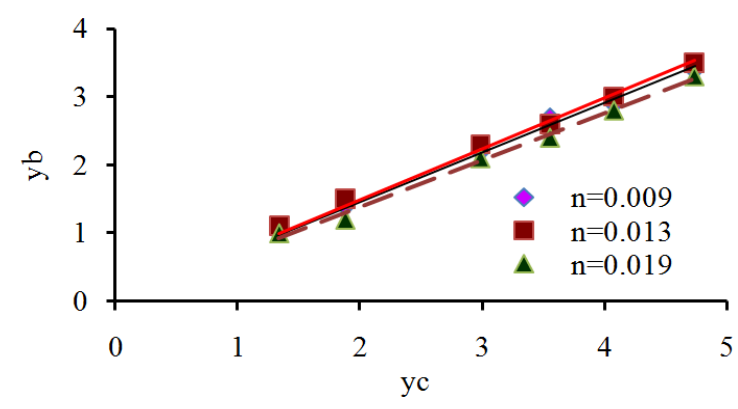

Fig. 5. EDR for $S_{o}=0.005$ and all roughness 


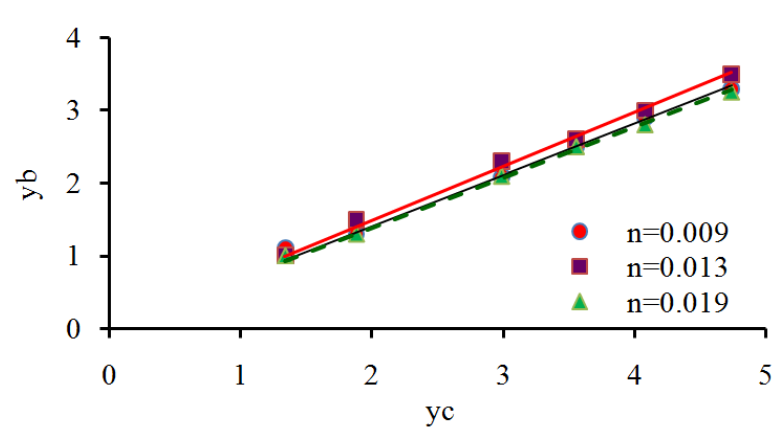

Fig. 6. EDR for $S_{o}=0.01$ and all roughness

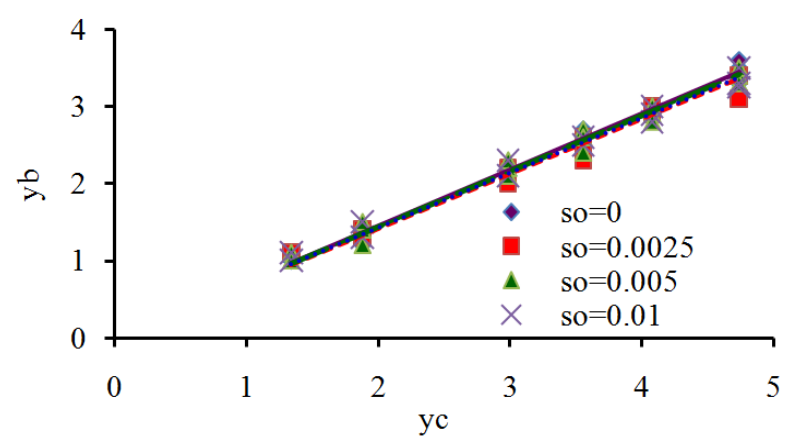

Fig. 7. Effect of slope on EDR

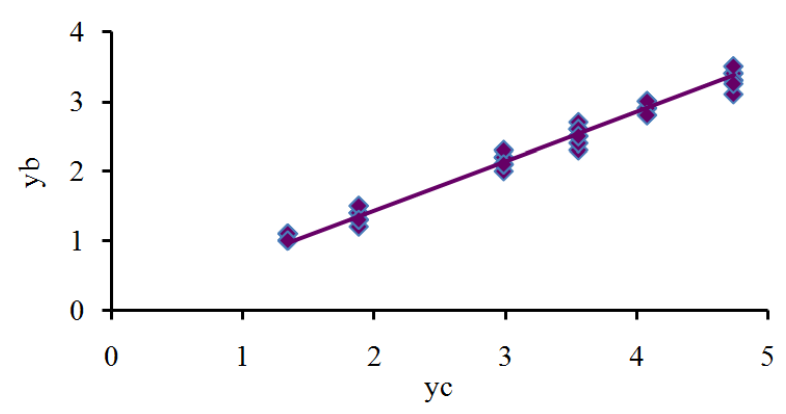

Fig. 8. General relationship of EDR for sloped bed

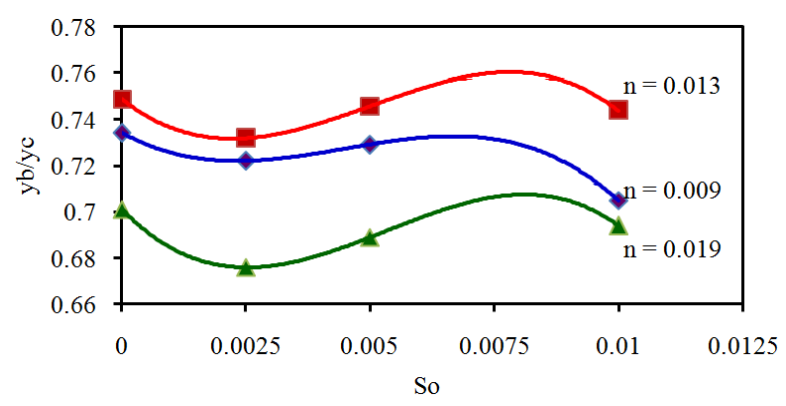

Fig. 9. EDR and slope relationship

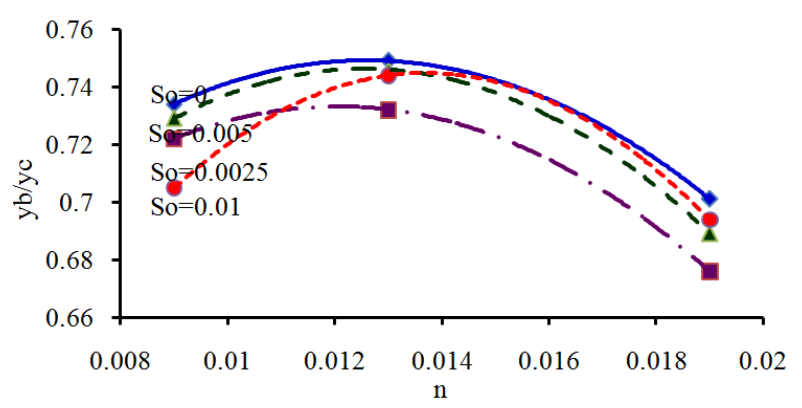

Fig. 10. EDR and roughness relationship

Figure 9 illustrate the variation trends of Equation $5 a-5 c$. This figure confirms the non-uniformity in the tendency of EDR with increasing the bed slope. However, the spaces between curves seem clear; that means clarity influence of roughness. On the opposite, the variation of EDR with a surface roughness having a regular behavior as shown in Fig. 10, the maximum and minimum values of $y_{b} / y_{c}$ were recorded with $n=0.013$ and 0.019 respectively. The family curves of Fig. 10 also illustrate that the EDR influenced with the variation of bed slope, the leaser value seems with $S_{o}=$ 0.0025 . The relevant relationships are:

$$
\begin{aligned}
& \frac{y_{b}}{y_{c}}=-1175 n^{2}+29.6 n+0.5628\left(R^{2}=1\right) \\
& \frac{y_{b}}{y_{c}}=-1808.3 n^{2}+49.533 n+0.4057\left(R^{2}=1\right) \\
& \frac{y_{b}}{y_{c}}=-1375 n^{2}+34.5 n+0.5299\left(R^{2}=1\right) \\
& \frac{y_{b}}{y_{c}}=-1183.3 n^{2}+28.533 n+0.561\left(R^{2}=1\right)
\end{aligned}
$$

\section{Theoretical Approach}

From the analysis, the impact characteristics of free overfall with upstream bed slope, Liu et al. (2014) used the law of momentum conservation between approaching section at which the normal depth $y_{n}$ exists and the depth at the brink of the drop. The authors presented the following equation of EDR after rearranging the governed variables:

$$
\frac{y_{b}}{y_{c}}=\frac{2 y_{n}}{y_{c}\left(F_{n}^{-2} \cos ^{2} \varnothing+2\right)}
$$

where, $F_{n}$, is a Froude number of normal flow depth and $\varphi$, is inclination angle of approach channel bed 
slope. By using a geometric and flow data of present work, the EDR was computed by Equation 7 and considered the theoretical ratios. The experimental results of the present study have been employed, on the other hand, to calculate the EDR. The coefficient, produced from dividing the EDR from experiment measurements to this obtained from Equation 7 (theoretical) is denoted as $K$. The average value of this coefficient for each roughness has been treated as a function depends on bed slope. Herein a functional relationship for $n=0.009$ to 0.019 as drawn and presented in Fig. 11 are:

$K=\frac{0.9406}{S_{o}^{0.036}}\left(R^{2}=0.5\right)$

$K=\frac{0.4118}{S_{o}^{0.219}}\left(R^{2}=0.951\right)$

$K=\frac{0.137}{S_{o}^{0.461}}\left(R^{2}=0.979\right)$

As seen from Fig. 11, the differences between trend lines decrease as the slope of bed increase and at $S_{o}=0.01$ no appreciable difference in $K$ for any roughness are recognized. That can be attributed to the decay of the effect of the roughness on the amount of Froude number and normal depth as the bed inclination increases. Moreover, for smooth bed, the value of $K$ seems nearly constant with all slopes undertaken. The advantage of Fig. 11 and its derived relationships are to use as a tool for predicting (K) parameter when $S_{o}$ given. Thereby, the actual EDR become easy to calculate when the measurements are available for both normal depth and related flow velocity. For horizontal slope, however, a linear relationship was resulted between $\mathrm{K}$ and $\mathrm{n}$, as shown in Fig. 12. This figure shows adverse proportionality between these variables with the following formula:

$K=0.786-26.524 n\left(R^{2}=0.996\right)$

\section{Discharge Calculation}

Figure 3 to 6 considered useful tools to predict EDR. These ratios have been employed as dependent parameters to extract a relationship related to $n$ and $S_{0}$. The correlation between EDR and slope and roughness for inclined bed rested to the following formula:

$\frac{y_{b}}{y_{c}}=0.6387\left(\frac{\sqrt{S_{o}}}{n}\right)^{0.0714}\left(R^{2}=0.51\right)$

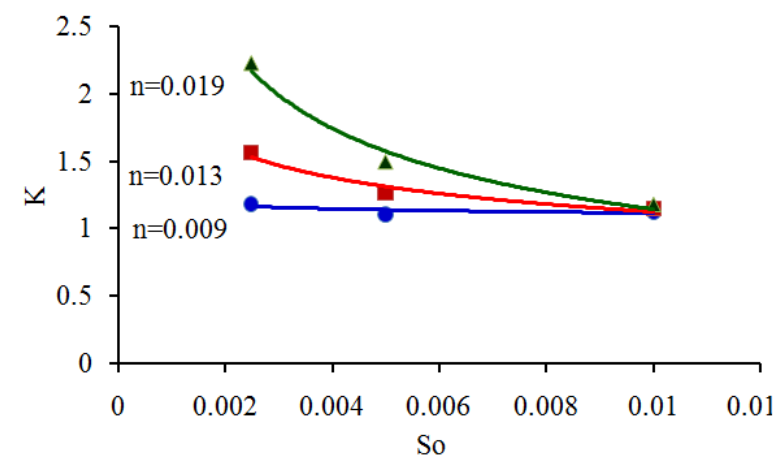

Fig. 11. Measured to theoritical EDR

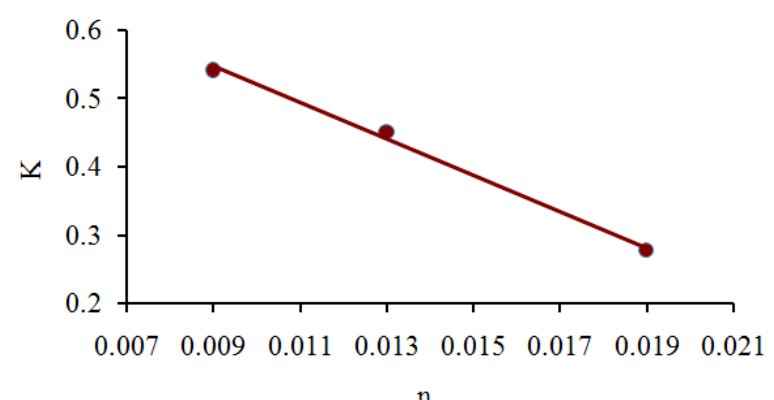

Fig. 12. Coefficient of EDR for $S_{o}=0$

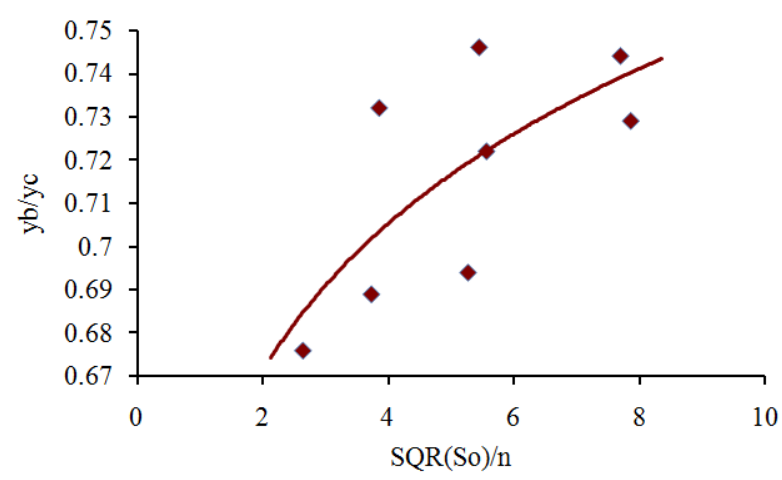

Fig. 13. EDR as a function of Slope and roughness

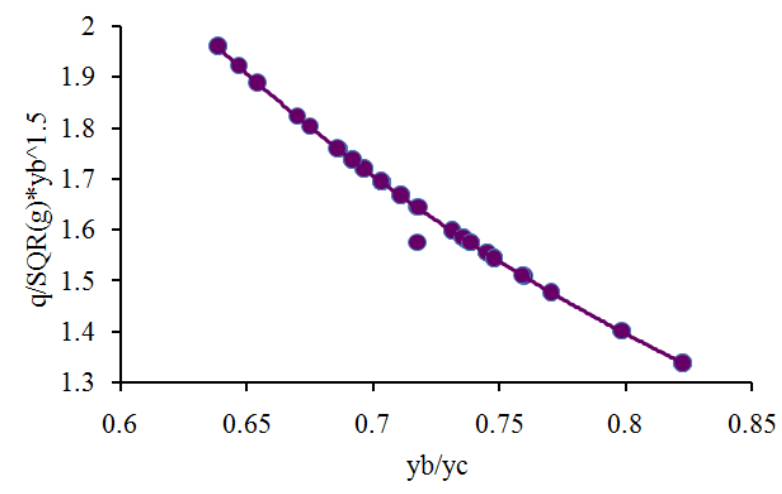

Fig. 14. General relationship for discharge calculation 
In practical application Equation 9 and its related Fig. 13 can be used to predict EDR when bed slope of approaching channel and roughness are known. The aim of site engineer is to measure or calculate the discharge, thus, as the EDR become known, the unit discharge, $q$ for a horizontal and inclined bed can easy to read from Fig. 14 or by using the following relevant formula for calculation:

$\frac{q}{\sqrt{g} y_{b}^{1.5}}=\frac{1}{\left(\frac{y_{b}}{y_{c}}\right)^{3 / 2}}\left(R^{2}=0.996\right)$

The application of Equation 9 and 10 or related figures is required to calculate the EDR from Fig. 3, Equation 5, or Equation 6.

On the site, there is a possibility to measure $y_{n}$ at a section upstream the brink still unaffected by drawdown. At the same time, there are difficult to know the real values of bed slope and roughness. At this practical situation, Equation 12 or Fig. 15 becomes a useful for solution, where the $\sqrt{S_{o}} / n$ that need for discharge calculation become known. The collected data by present experimental work have been invested to prepare Fig. 15 and the related formula was:

$$
\frac{\sqrt{S_{o}}}{n}=\frac{2.13}{\left(\frac{y_{n}}{b}\right)^{1.338}}\left(R^{2}=0.991\right)
$$

where, $b$, is the width of approach channel. The results of the laboratory work also allowed to developing relationships link between normal depth and flow depth at the brink and Fig. 16 and 17 depict these correlations. The related dimensionless equations are according to the following power form:

$$
\frac{y_{b}}{b}=a\left(\frac{y_{n}}{b}\right)^{b}
$$

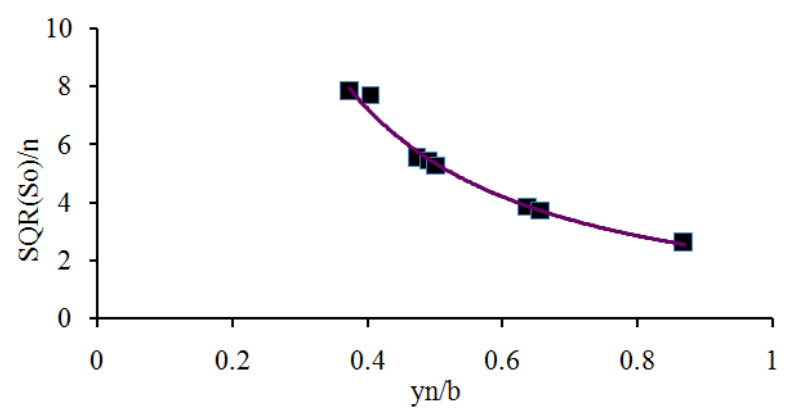

Fig. 15. Bed slope and roughness related to normal depth

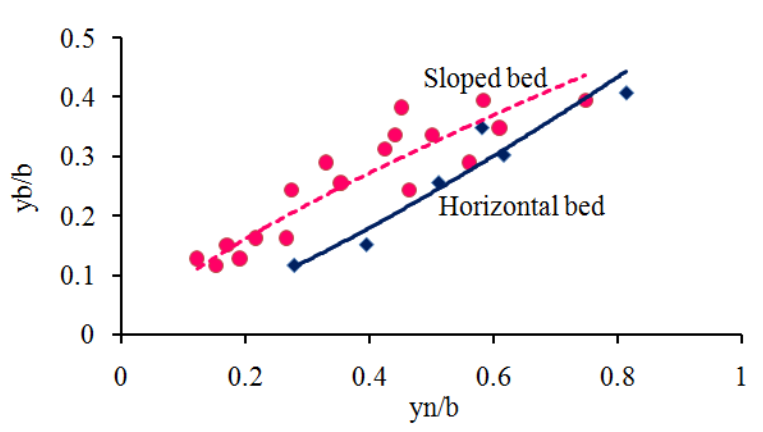

Fig. 16. The relationship between brink and normal depths for smooth bed

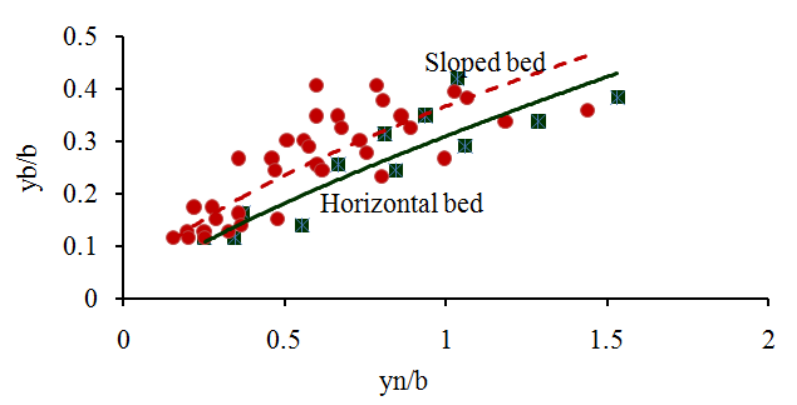

Fig.17. The relationship between brink and normal depths for rough beds

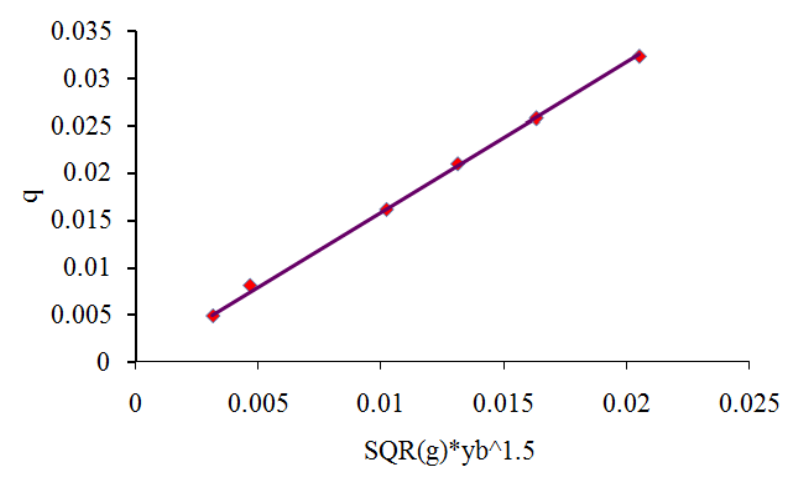

Fig. 18. Coefficient of discharge for smooth and horizontal bed

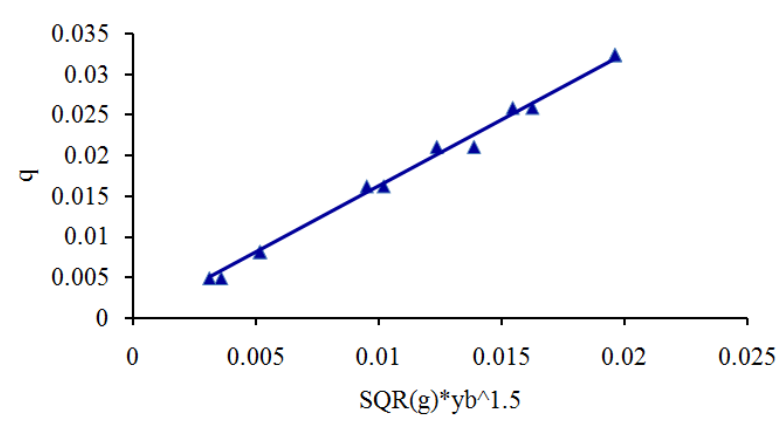

Fig. 19. Coefficient of discharge for smooth and sloped bed 
Table 2. Statistical parameters of Equation 13

\begin{tabular}{llll}
\hline Slope and Roughness & $\mathrm{a}$ & $\mathrm{b}$ & $\mathrm{R}^{2}$ \\
\hline Horizontal bed slope and $n=0.009$ (smooth) & 0.5766 & 1.2784 & 0.9425 \\
Inclined bed slope and $n=0.009$ (smooth) & 0.5429 & 0.7521 & 0.8698 \\
Horizontal bed slope and all Roughness & 0.3092 & 0.7696 & 0.8489 \\
Inclined bed slope and all Roughness & 0.3661 & 0.6422 & 0.7434 \\
\hline
\end{tabular}

Table 3. Discharge coefficients for Equation 14

\begin{tabular}{lll}
\hline Application case & $C_{d}$ & $R^{2}$ \\
\hline Smooth and horizontal bed & 1.5864 & 0.998 \\
Smooth and inclined bed & 1.624 & 0.994 \\
Rough and horizontal bed & 1.61 & 0.986 \\
Rough and inclined bed & 1.6593 & 0.979 \\
\hline
\end{tabular}

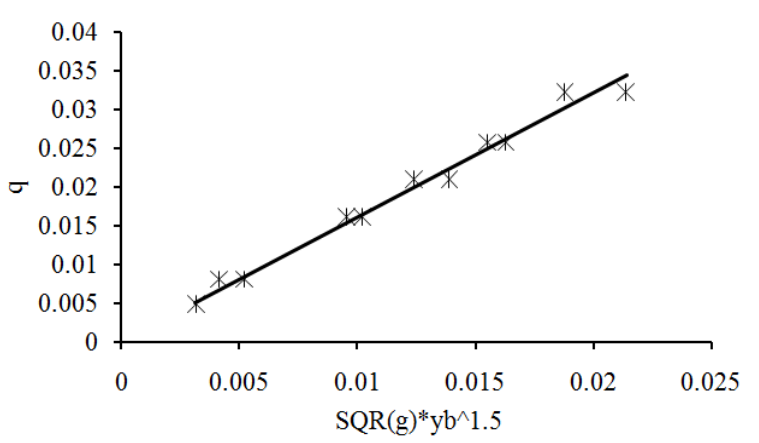

Fig. 20. Coefficient of discharge for rough and horizontal bed

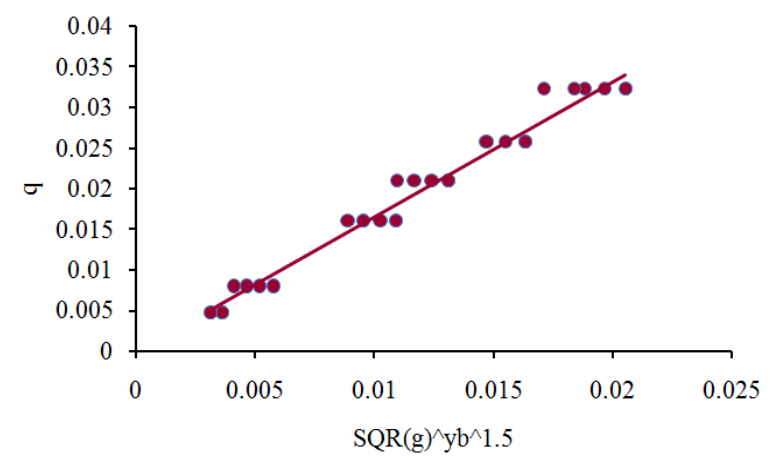

Fig. 21. Coefficient of discharge for rough and sloped bed

The coefficients, exponents and the determination coefficients of Equation 13 for a specified case of slope and roughness listed in Table 2. In practice, Equation 13 becomes a useful to calculate a discharge when it is hard to measure the brink depth or not provide an instrumentation to achieve the measure.

\section{Direct Relationship between Discharge and Brink Depth}

The laboratory results also invested in finding a relationship between the unit discharge, $q$ and the brink depth, $y_{b}$. This relationship takes the following general form:

$$
q=C_{d} \sqrt{g}\left(y_{b}\right)^{3 / 2}
$$

The aim of this analysis is to indicate the appropriate discharge coefficient, $C_{d}$ for each case of slope and roughness. Figure 18 to 21 illustrates the relationships for various cases. The $C_{d}$ for each design case listed in Table 3.

\section{Conclusion}

This study focused on analyses of experimental investigation data collected for flow over the free vertical drop to take into consideration the effect of roughness and slope of the upstream channel on End Depth Ratio (EDR). Different practical situations considered in the analysis of data. Thus various design and predictive equation with relevant figures are proposed by using the collected data at different features.

\section{Acknowledgment}

The Author likes to thank the staff member of Hydraulic Laboratory for approval of the use flume and measurement facilities and for assistance in preparing models. Deeply acknowledge to Building and Construction Engineering the UOT/Baghdad for academic assistance.

\section{Ethics}

Any ethical issues that may arise after the publication of this manuscript are under the author responsibility.

\section{References}

Ali, K.H.M. and A. Sykes, 1972. Free-vortex theory applied to free overfalls. J. Hydr. Divis., 98: 973-979.

Davis, A.C., B.G.S. Ellett and R.P. Jacob, 1998. Flow measurement in sloping channels with rectangular free overfall. J. Hydr. Eng., 124: 760-763. DOI: 10.1061/(ASCE)0733-9429(1998)124:7(760)

Delleur, J.W., J.C. Dooge and K.W. Gent, 1956. Influence of slope and roughness on the overfall. J. Hydr. Eng., 82: 30-35.

Diskin, M.H., 1961. End depth of a drop in trapezoidal channels. J. Hydr. Eng., 87: 911-932.

Fathy, A. and M.A. Shaarawi, 1954. Hydraulics of the free overfall. Proceedings of the ASCE, (ASCE' 54), New York. 
Ferro, V., 1992. Flow measurement with rectangular free overfall. J. Irrg. Drain. Eng., 118: 956-964. DOI: 10.1061/(ASCE)0733-9437(1992)118:6(956)

Ferro, V., 1999. Theoretical end depth discharge relationship for free overfall. J. Irrg. Drain. Eng., 125: 40-44.

Firat, C.E., 2004. Effect of roughness on flow measurements in sloping rectangular channels with free overfall. MSc Thesis, Middle East Tech. Univ.

Gupta, R.D., M. Jamil and M. Mohsin, 1993. Discharge prediction in smooth trapezoidal free overfall(positive, zero and negative slopes). J. Irrig. Drain. Eng., 119: 215-224.

DOI: 10.1061/(ASCE)0733-9437(1993)119:2(215)

Hong, Y.M., H.S. Huang and S. Wan, 2010. Drop characteristics of free-falling nappe for aerated straight-drop spillway. J. Hyd. Res., 48: 125-129. DOI: $10.1080 / 00221680903568683$
Kraijenhoff, D.A. and A. Dommerholt, 1977. Brink depth method in rectangular channel. J. Irrig. Drain. Eng., 103: 171-177.

Liu, S.I., J.Y. Chen, Y.M. Hong, H.S. Huang and R.V. Raikar, 2014. Impact characteristics of free over-fall in pool zone with upstream bed slope. J. Marine Sci. Technol., 22: 467-486. DOI: 10.6119/JMST-013-0604-1

Mays, L.W., 2010. Water Resources Engineering. 2nd Edn., John Wiley and Sons, Inc., Hoboken, ISBN-10: 0470460644, pp: 890.

Rajaratnam, N. and D. Muralidhar, 1964a. End depth for exponential channels. J. Irrig. Drain. Eng., 90: 17-36.

Rajaratnam, N. and D. Muralidhar, 1964b. End depth for circular channels. J. Hydr. Eng., 90: 99-119.

Rouse, H., 1936. Discharge characteristics of free overfall. J. Civil Eng., 6: 257-260.

Smith, C.D., 1962. Brink depth for a circular channel. J. Hydr. Eng., 89: 125-134. 